\title{
Effect of Pioglitazone on Nitroglycerin-Induced Impairment of Nitric Oxide Bioavailability by a Catheter-Type Nitric Oxide Sensor
}

\author{
Hideyuki Ikejima, MD; Toshio Imanishi, PhD; Hiroto Tsujioka, MD; Akio Kuroi, MD; \\ Yasuteru Muragaki, PhD*; Seiichi Mochizuki, PhD**; Masami Goto, PhD**; \\ Kiyoshi Yoshida, $\mathrm{PhD}^{\dagger}$; Takashi Akasaka, $\mathrm{PhD}$
}

\begin{abstract}
Background We examined whether nitroglycerin (NTG)-induced impairment of nitric oxide (NO) bioavailability could be modified by a peroxisome proliferator-activated receptor (PPAR)Y agonist.

Methods and Results Male New Zealand White rabbits were treated for 7 days with NTG patches, either alone or in combination with pioglitazone. Plasma NO concentration was measured with the catheter-type NO sensor located in the aorta. $\mathrm{NG}_{-}$-methyl-L-arginine and acetylcholine ( $\mathrm{ACh}$ ) were infused into the aortic arch to measure the basal and ACh-induced plasma NO concentrations. Vascular nitrotyrosine and tetrahydrobiopterin $\left(\mathrm{BH}_{4}\right)$ concentrations were measured by enzyme-linked immunosorbent assay and high-performance liquid chromatography with fluorescence detection, respectively. The negative effects of NTG, that is, the decrease in basal and ACh-induced NO production, were significantly suppressed by co-treatment with pioglitazone. NTG-induced increases in vascular nitrotyrosine and $\mathrm{BH}_{4}$ concentrations were significantly decreased with co-treatment with pioglitazone.

Conclusions NTG-induced impairment of basal and ACh-stimulated NO production might be prevented by the co-treatment with a PPARY agonist, pioglitazone through suppressions of nitrosative stress. (Circ J 2008; 72: 998 -1002)
\end{abstract}

Key Words: Nitrate tolerance; Nitric oxide; Nitric oxide sensor; Nitrosative stress

$\mathbf{S}$ everal clinical and basic studies have shown that chronic treatment with nitroglycerin (NTG) causes endothelial dysfunction ${ }^{1-3}$ However, the limitation of these data is that the release of nitric oxide (NO) from the endothelium was estimated on the basis of the comparison of vessel relaxation. We have very recently shown that longterm treatment of New Zealand White rabbits with NTG decreases basal, as well as acetylcholine (ACh)-induced plasma NO concentrations by using a catheter-type NO sensor, accompanied with augmentation of nitrosative stress. ${ }^{4}$ In addition, we have shown that the negative effects of NTG could be prevented by co-treatment with drugs attenuating nitrosative stress, such as, angiotensin-converting enzyme inhibitors and angiotensin II type 1 receptor blockers (ARB).

The peroxisome proliferator-activated receptor (PPAR)Y is a nuclear receptor that has recently emerged as a pivotal intracellular controller of systemic and vascular processes, including inflammation and atherosclerosis? PPARY is expressed in all major cell types involved in the initiation and evolution of the atherosclerotic plaque, including endothelial cells, vascular smooth muscle cells, macrophages, and

(Received September 12, 2007; revised manuscript received January 14, 2008; accepted January 17, 2008)

Department of Cardiovascular Medicine, *Department of Pathology, Wakayama Medical University, Wakayama, **Department of Medical Engineering and Division of Cardiology, Kawasaki Medical School, Okayama, Japan

Mailing address: Toshio Imanishi, MD, Department of Cardiovascular Medicine, Wakayama Medical University, 811-1 Kimiidera, Wakayama 641-8510, Japan. E-mail: t-imani@ wakayama-med.ac.jp All rights are reserved to the Japanese Circulation Society. For permissions, please e-mail: cj@j-circ.or.jp
T lymphocytes, where it might exert anti-inflammatory and potentially anti-atherogenic effects? Interestingly, PPARY stimulation improves insulin resistance as well as endothelial function in patients with type 2 diabetes? However, it is unknown whether this beneficial effect of PPARy stimulation on endothelial function could extend to NTG-induced endothelial dysfunction. It is clinically important because patients with diabetes mellitus have frequently accompanied with ischemic heart disease.

By using the catheter-type NO sensor we investigated to clarify the effect of PPARY agonist on the impairment of bioavailability of NO induced by chronic treatment with NTG patches. The present study has shown that the NTGinduced impairment of $\mathrm{NO}$ bioavailability is significantly reversed by the co-treatment with a PPARY agonist, pioglitazone.

\section{Methods}

\section{A Catheter Type NO Sensor}

Integrated architecture and performance of the cathetertype NO sensor have been described previously ${ }^{8-10}$ In brief, an NO sensor (amino-700 XL, Innovative Instruments, $700 \mathrm{\mu} \mathrm{m}$ in diameter at the detection tip) was mounted in a 4-Fr catheter (1,200 mm long; Hirakawa Hewtech, Tokyo, Japan) and fixed with silicon adhesive. The oxidative current of NO was monitored by with an NO monitor (model inNO-T, Innovative Instruments). Each sensor was calibrated by using an NO-saturated pure water as previously described ${ }^{8-10}$ Briefly, NO-saturated pure water was prepared by bubbling pure NO gas in oxygen-free pure water. Using a gas-tight syrindge, $5 \mu 1$ was injected into a well 
stirred saline solution $(50 \mathrm{ml})$ in which the NO sensor was immersed (final NO concentration: $190 \mathrm{nmol} / \mathrm{L}$ ) as previously described8-10 The baseline (zero level) is set arbitrarily in the amperometric method, and thus, a peak change in the current form from the baseline is used and is expressed as 'change in NO concentration (nmol/L)' because NO concentration cannot be measured as an absolute value with the amperometric method? ${ }^{-10}$

\section{Animal Preparations}

The study protocol was approved by the Institutional Animal Care and Use Committee of Wakayama Medical University. Male New Zealand White rabbits $(2.0-2.5 \mathrm{~kg}$ ) were maintained on tap water and standard diet. The animals were randomized into 1 of 4 experimental groups. Group $1(n=6)$ was allocated to control, whereas groups 2, 3 and $4(n=6$ per group) were treated with transdermal NTG patches (Nihon Kayaku Pharma, Tokyo, Japan) to a shaved dorsal thoracic area of the body. Such patches were present continuously for a period of 7 days (each patch being replaced daily with a new one patch). The theoretical delivery of NTG was $0.5 \mathrm{mg} / \mathrm{h}$. Group 2 was treated with transdermal NTG patches alone for 7 days. In addition to the NTG, $1 \mathrm{mg} \cdot \mathrm{kg}^{-1} \cdot$ day $^{-1}$ or $3 \mathrm{mg} \cdot \mathrm{kg}^{-1} \cdot$ day $^{-1}$ of pioglitazone (Takeda Pharma, Osaka, Japan) mixed in oral gavage was administered (Group 3 and 4, respectively). Only animals with stable fixed NTG patches during $24 \mathrm{~h}$ were included in the present study. Rabbits were anesthetized with xylazine (10 mg/kg intramuscularly), ketamine $(50 \mathrm{mg} / \mathrm{kg}$ intramuscularly), and pentobarbital sodium (10 mg/kg intravenous), followed by heparin (1,000 units intravenous) for anticoagulation. A catheter for ACh infusion was inserted from the external carotid artery and located at the point, where pressure wave patterns change from left ventricular pressure to aortic pressure. The NO sensor was inserted through the left femoral artery and located in the descending aorta at costal arch under radiographic guidance. Aortic blood pressure was simultaneously monitored through a stiff cannula with a strain gauge pressure transducer (Nihon Kohden, Tokyo, Japan).

\section{Experimental Protocol}

To measure the endothelium-dependent NO production, $20 \mathrm{~g} / \mathrm{kg}$ of $\mathrm{ACh}$ was administered at $1 \mathrm{ml} / \mathrm{min}$ for $5 \mathrm{~min}$. To inhibit $\mathrm{NO}$ synthesis in the endothelium, $5 \mathrm{mg} / \mathrm{kg}$ of $\mathrm{NG}_{-}$ methyl-L-arginine (L-NMMA, NO synthesis inhibitor) was infused at $1 \mathrm{ml} / \mathrm{min}$ for $10 \mathrm{~min}$ to inhibit $\mathrm{NO}$ synthesis. Plasma NO concentration in the thoracic aorta was monitored over the entire time course.

\section{Measurement of Vascular Nitrotyrosine}

Active NO metabolites can react with superoxide to form peroxynitrite and nitrating oxidant. Subsequent reaction of peroxinitrite with proteins results in nitrotyrosine formation. As a stable end product of peroxinitrite mediated oxidation/nitration, nitrotyrosine can be used as a surrogate index of adverse NO dependent damage in vivo. Therefore, we investigated the effect of chronic treatment with NTG on nitrotyrosine formation. For analyzing the vascular nitrotyrosine, NWLSS nitrotyrosine enzyme-linked immunosorbent assay (ELISA) kit (Northwest Life Science Specialities, LLC, Vancouver, Canada) was used according to the manufacturer's protocol. The NWLSS nitrotyrosine ELISA kit measures nitrosylated protein and not 'free' nitrotyrosine. Samples do not need to be hydrolyzed and data should be interpreted as being inclusive of nitrotyrosine still bound to soluble proteins.1 1 The kit is a simple 'sandwich' ELISA using a plate bound capture antibody to nitrotyrosine and a biotinylated secondary tracer antibody. Addition of streptavidine-peroxidase followed by tetramethylbenzidine facilitates color development. The amount of bound protein in each well was measured with an ELISA Plate Reader (Bionetics Laboratory, Kensington, MD, USA) at $450 \mathrm{~nm}$.

\section{Measurement of Tetrahydrobiopterin ( $\left.\mathrm{BH}_{4}\right)$ in Aortic Segments}

Measurement of $\mathrm{BH}_{4}$ by high-performance liquid chromatography with fluorescence detection is based on the quantification of biopterin, a highly fluorescent $\mathrm{BH}_{4}$ analogue!2 Oxidation of $\mathrm{BH}_{4}$ to biopterin under acidic conditions is quantitative. Under basic conditions, however, $\mathrm{BH}_{4}$ is further oxidized to non-fluorescent compounds. Thus, $\mathrm{BH} 4$ concentrations are calculated from the difference of biopterin measured in these conditions. Frozen aortic segments from vehicle (control-), NTG-, and NTG+pioglitazone-treated rabbits were cryopulverized and divided into 2 fractions of known weight. One fraction was suspended in $\mathrm{HCl}(0.25 \mathrm{ml}$, $0.1 \mathrm{~N})$, and the other was suspended in $\mathrm{NaOH}(0.3 \mathrm{ml}, 0.1 \mathrm{~N})$. Each fraction was sonicated twice on water/ice bath for $1 \mathrm{~min}$ by use of $25 \%$ sonicator full-power potency to break open the cells. After a 90-min incubation at room temperature, $50 \mathrm{~L}$ of a $50 \%$ ascorbate solution was added to remove excess iodine solution and then centrifuged at $14,000 \mathrm{rpm}$ for $10 \mathrm{~min}$ to remove tissue debris. After adjustment of $\mathrm{pH}$ to 4.0 with $\mathrm{HCl}$, supernatants were injected onto a Kromasil C18 coluum equilibrated with phosphate buffer $(0.15 \mathrm{mmol} / \mathrm{L}$, pH 6.4), and biopterin was analyzed by authentic standards.

\section{Statistical Analysis}

All data were expressed as mean \pm SEM based on at least 6 independent experiments. Statistical analyses for comparison of changes in plasma NO concentration by $\mathrm{ACh}$ were conducted by paired t-test. Difference in values between groups and treatments were tested using 1-way ANOVA of repeated measurements, followed by the post hoc Scheffe F test. A probability value of $<0.05$ were considered significant.

\section{Results}

\section{Calibration of Sensors}

The basic performance of the integrated catheter-type NO sensors was reported in our previous studies? ${ }^{-10}$ The NO sensors showed no noticeable change in response to oxygen, $\mathrm{ACh}$, and solution mixing, indicating high specificity to NO (data not shown). The mean sensitivity of the 7 sensors used in the present study was $317 \pm 13 \mathrm{pA} \cdot \mathrm{nmol} / \mathrm{L}$. This value is comparable to the values of the original in vivo sensor ${ }^{3}$

\section{Effect of Pioglitazone on ACh-Induced and Basal Plasma NO Concentration in NTG-Treated Rabbits}

As previously described, 4 treatments of rabbits with NTG for 7 days resulted in a significant reduction in the increase in plasma NO concentration induced by ACh and L-NMMA (Figs 1 and 2, respectively). Furthermore, pioglitazone significantly abolished NTG-induced impairment of ACh-induced plasma NO concentration (Fig 1) in a dose-dependent manner. Similarly, pioglitazone significantly improved basal plasma NO concentration in a dose-dependent manner, although not attained statistically significant (Fig 2). 
A

\section{Control}

NTG

NTG

+ Pioglitazone

$\left(\mathbf{m g} \cdot \mathrm{kg}^{-1} \cdot \mathrm{day}^{-1}\right)$

NTG

+ Pioglitazone

$\left(3 \mathrm{mg} \cdot \mathrm{kg}^{-1} \cdot \mathrm{day}^{-1}\right)$
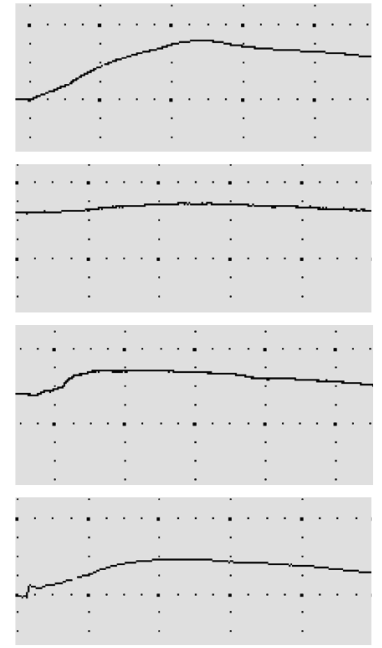

$\uparrow$

$$
\uparrow
$$

ACh injection
$6 \mathrm{nmol} / \mathrm{L}$
B

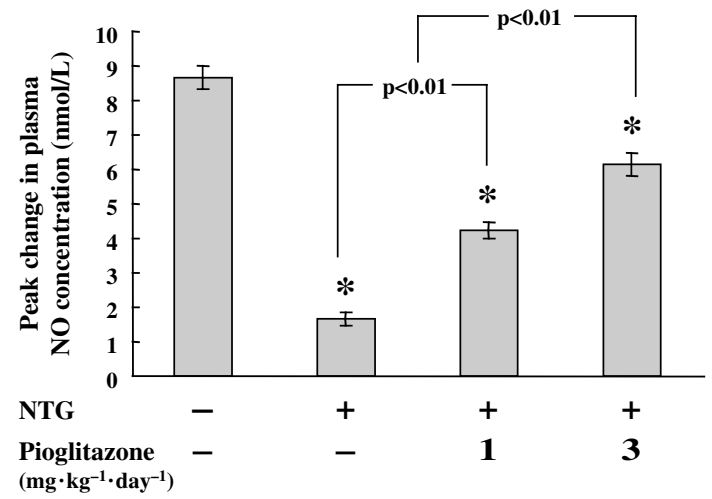

Fig 1. Effect of chronic treatment with nitroglycerin (NTG) either alone or in combination with pioglitazone on acetylcholine (ACh)-induced plasma nitric oxide (NO) concentration. (A) Typical tracings of the plasma NO concentration induced by Ach in thoracic aorta treated with vehicle (control), NTG, NTG+pioglitazone $\left(1 \mathrm{mg} \cdot \mathrm{kg}^{-1} \cdot \mathrm{day}^{-1}\right)$, and NTG+ pioglitazone $\left(3 \mathrm{mg} \cdot \mathrm{kg}^{-1} \cdot \mathrm{day}^{-1}\right)$. (B) NTG-induced impairment of ACh-induced NO bioavailability was significantly attenuated by co-treatment with pioglitazone. Data are expressed as the mean $\pm \operatorname{SEM}(n=6)$. ${ }^{*} \mathrm{p}<0.01$ compared with control group.

A
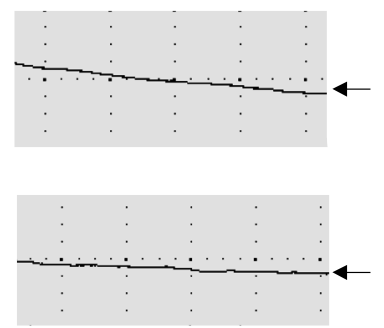

NTG

Control

oglitazone $\left(1 \mathrm{mg} \cdot \mathrm{kg}^{-1} \cdot \mathrm{day}^{-1}\right)$

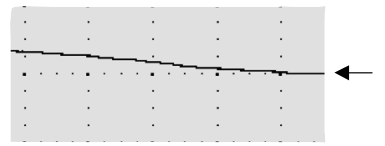

NTG + Pioglitazone $\left(3 \mathrm{mg} \cdot \mathrm{kg}^{-1} \cdot \mathrm{day}^{-1}\right)$
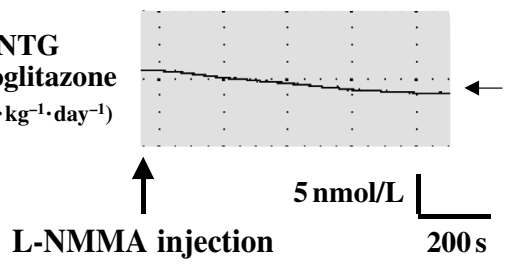

B

$\begin{array}{lllll}\text { NTG } & - & + & + & + \\ \begin{array}{l}\text { Pioglitazone } \\ \left(\mathrm{mg} \cdot \mathrm{kg}^{-1} \cdot \mathbf{d a y}^{-1}\right)\end{array} & - & - & 1 & 3\end{array}$

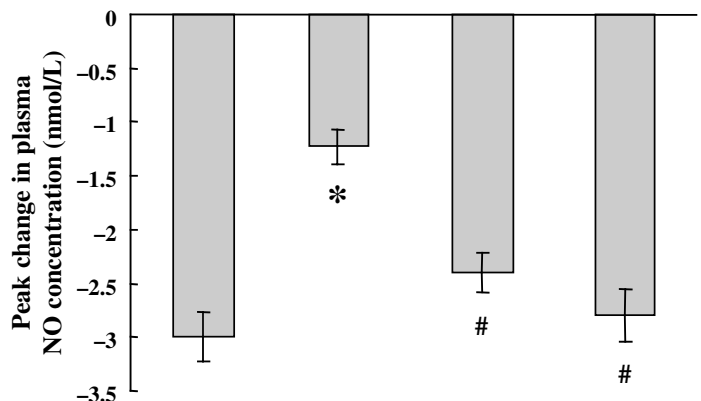

Fig 2. Effect of chronic treatment with nitroglycerin (NTG) either alone or in combination with pioglitazone on basal plasma nitric oxide (NO) concentration by $\mathrm{N}^{\mathrm{G}}$-methyl-L-arginine (L-NMMA, NO synthesis inhibitor). (A) Typical tracings of the basal plasma NO concentration induced by L-NMMA in thoracic aorta treated with vehicle (control), NTG, NTG+ pioglitazone $\left(1 \mathrm{mg} \cdot \mathrm{kg}^{-1} \cdot \mathrm{day}^{-1}\right)$, and NTG+pioglitazone $\left(3 \mathrm{mg} \cdot \mathrm{kg}^{-1} \cdot \mathrm{day}^{-1}\right)$. (B) NTG-induced impairment of basal NO bioavailability was significantly attenuated by co-treatment with pioglitazone. Data are expressed as the mean \pm SEM $(\mathrm{n}=6) .{ }^{*} \mathrm{p}<0.01$ compared with control group. ${ }^{\#} \mathrm{p}<0.01$ compared with NTG-treated group.

\section{Effect of Pioglitazone on Vascular Nitrotyrosine in NTG-Treated Rabbits}

Having showed that pioglitazone exerted preserved plasma NO concentration in aorta treated with NTG, we investigated the effect of pioglitazone on vascular nitrative stress associated with NTG. To this end, we determined the vascular nitrotyrosine content by ELISA. Although the NTG-treated rabbits had significantly higher vascular nitrotyrosine concentrations compared with that of the control, co-treatment with pioglitazone abolished the increase in vascular nitrotyrosine in a dose-dependent manner, although not attained statistically significant (Fig 3). 


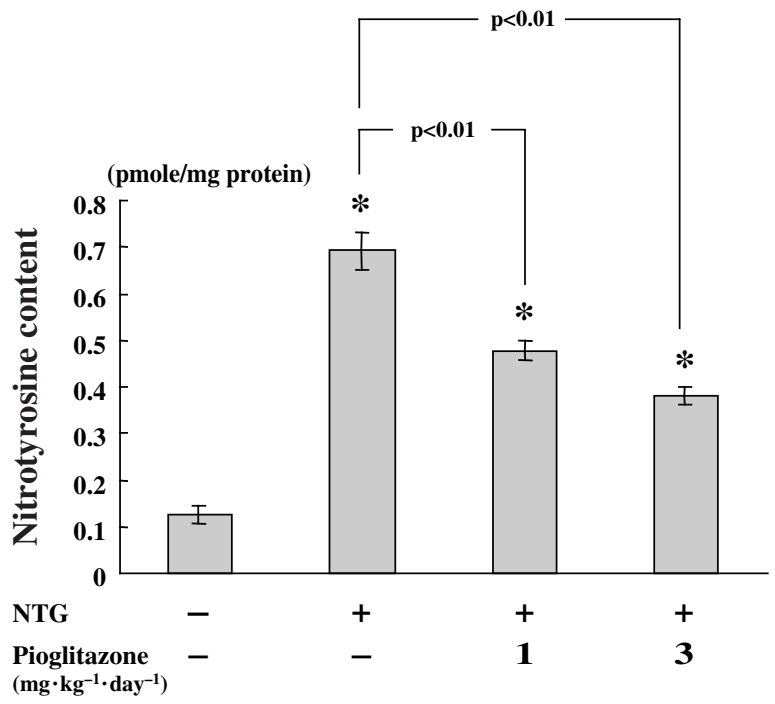

Fig 3. Effect of chronic treatment with nitroglycerin (NTG) either alone or in combination with pioglitazone on vascular nitrotyrosine. The levels of vascular nitrotyrosine were detected as described in the Methods section. Data are expressed as the mean \pm SEM $(n=6)$. $* \mathrm{p}<0.01$ compared with control group.

\section{Effects of Pioglitazone on Vascular $\mathrm{BH}_{4}$ Levels in NTG-Treated Rabbits}

Because $\mathrm{BH}_{4}$ is of fundamental importance of the normal endothelial NO synthase (eNOS), we examined the effects of pioglitazone on vascular $\mathrm{BH}_{4}$ concentrations. We observed that NTG-treatment significantly decreased vascular $\mathrm{BH}_{4}$ concentrations compared with vessels from received vehicle (control) (Fig 4). Furthermore, the NTG-induced decrease in vascular $\mathrm{BH} 4$ concentrations was significantly reversed by co-treatment with pioglitazone in a dose-dependent manner, although not attained statistically significant (Fig4).

\section{Discussion}

There is considerable evidence that nitrate tolerance is associated with incremental impairment of endothelial function! ${ }^{1-3}$ This cross-tolerance to endogenous NO would imply that nitrate therapy might be potentially harmful to longterm clinical outcomes. In the present study, we have shown for the first time that NTG-induced impairment of NO bioavailability could be improved by co-treatment with a PPARy agonist, pioglitazone.

In this study, we used in vivo treatment of New Zealand White rabbits with an NTG patch as an established nitrate tolerance/cross tolerance animal model according to previous reports ${ }^{14-17}$ In a previous study, we confirmed that this treatment results in significant endothelial dysfunction with an endothelial-dependent vasorelaxation method in aortic ring. In addition, Gori et al have shown that continuous NTG treatment induces significant changes in the function of the endothelium in humans ${ }^{18}$ However, in this study, we could not evaluate the extent to which exogenous NO, such as ambient environment, food, and water, affected our results. Further studies will be needed on this subject.

In our previous studies, the direct in vivo endotheliumderived NO was measured with a catheter-type NO sensor in the rabbit model.,10 The NO sensor was shown to be stable and specific to NO because the direct exposure to either ACh or L-NMMA solution did not cause any significant

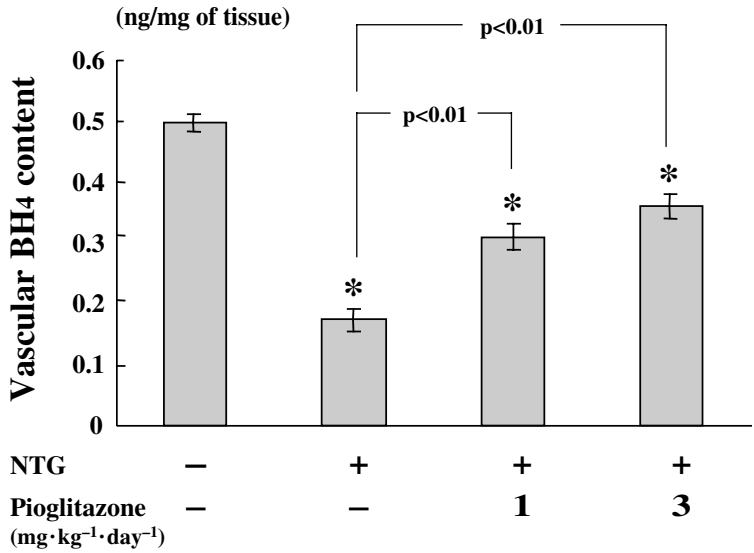

Fig 4. Tetrahydrobiopterin $\left(\mathrm{BH}_{4}\right)$ concentrations in thoracic aorta treated with vehicle (control), nitroglycerin (NTG), NTG+pioglitazone $\left(1 \mathrm{mg} \cdot \mathrm{kg}^{-1} \cdot \mathrm{day}^{-1}\right)$ and $\mathrm{NTG}+$ pioglitazone $\left(3 \mathrm{mg} \cdot \mathrm{kg}^{-1} \cdot \mathrm{day}^{-1}\right)$. Bars represent mean $\pm \mathrm{SEM} ; \mathrm{n}=6$ separate experiments. $* \mathrm{p}<0.01$ compared with control group.

change in the baseline current (data not shown). The NO sensor was shown no noticeable change in the baseline current because of solution mixing, suggesting that it was not affected by fluid (blood) motion (data not shown). Thus, this system has high specificity for NO, and the monitored current reflected the change in plasma concentration of $\mathrm{NO}$ released from the endothelium after ACh and L-NMMA infusions.

The present study has demonstrated that pioglitazone abolished NTG-induced impairment of ACh-induced NO production in a dose-dependent manner. In addition, pioglitazone also abolished NTG-induced increase in vascular nitrotyrosine, and NTG-induced decrease in vascular $\mathrm{BH}_{4}$ concentrations in a dose-dependent manner, although not attained statistically significant. There are several potential mechanisms by which pioglitazone might exert its endothelial protection in rabbits treated with NTG. One possible mechanism is the reduction of nitrosative stress in pioglitazone-treated rabbits as evidenced by reduced nitrotyrosine formation in the present study. A stable metabolite of peroxynitrite, nitrotyrosine, is formed by nitration of tyrosine, either free or protein bound. Increased vascular peroxynitrite formation might affect the proper function of eNOS and thus induce the impairment of bioavailability of NO. As pointed out by Gori et $\mathrm{al}^{2}$, peroxynitrite is a strong stimulus for the oxidation of the eNOS cofactor $\mathrm{BH}_{4}$ to dihydrobiopterin. The resulting intracellular $\mathrm{BH}_{4}$ deficiency might switch eNOS from a NO to a superoxide-producing enzyme, which may further increase oxidative stress in vascular tissue in a positive feedback fashion. In fact, we showed in the present study that NTG treatment resulted in intracellular $\mathrm{BH}_{4}$ depletion, whereas co-treatment with pioglitazone significantly improved the NTG-induced effects. This finding is in line with our recent findings, ${ }^{19}$ where exogenous NO suppresses the flow-induced, endothelium-derived NO production by superoxide released from uncoupled eNOS because of intracellular $\mathrm{BH}_{4}$ depletion. Taken together, pioglitazone might exert significant endothelial protective effects during long-term NTG therapy through the reduction of nitrosative stress. According to this oxidative stress theory, increased vascular superoxide $\left(\mathrm{O}_{2}{ }^{-}\right)$production and an increased sensitivity to vasoconstrictors secondary to activation of protein kinase $\mathrm{C}$ (PKC) contribute to the de- 
velopment of tolerance. Nicotinamide adenine dinucleotide phosphate oxidase and the uncoupled eNOS might be $\mathrm{O}_{2}^{-}-$ producing enzymes ${ }^{20} \mathrm{NO}$ and $\mathrm{O}_{2}^{-}$, both derived from NTG and the vessel wall, form peroxynitrite. Peroxynitrite, $\mathrm{O}_{2}$, or both might be responsible for the development of nitrate tolerance ${ }^{21}$ In addition, NTG is a potent stimulus for PKC activation in cultured endothelial cells, and inhibition of PKC prevents in vivo nitrate tolerance ${ }^{21}$ Because PKC activation is induced by $\mathrm{O}_{2}{ }^{-}$and peroxynitrite ${ }^{22}$ NTG might initiate a vicious cycle that involves activation of PKC, increased $\mathrm{O}_{2}^{-}$and peroxynitrite, depletion of $\mathrm{BH}_{4}$, and uncoupling of eNOS. NTG-induced increases in oxidative stress could also lead to increased production of endothelin1 within endothelial and smooth muscle cells, leading to PKC activation, which in turn may trigger enhanced constrictor responses to almost every receptor-dependent agonist $2^{23-25}$ Finally, NTG tolerance-induced superoxide and peroxynitrite formation could also interfere with nitrovasodilator action at the level of soluble guanylyl cyclase (sGC)? 26,27 This inhibition of sGC in nitrate tolerance may contribute to reduced NO bioavailability to NTG. Taken together, these oxidative stress-induced molecular changes may relate to the mechanisms underlying nitrate tolerance. However, Sydow et al have shown that mitochondrial aldehyde dehydrogenase (ALDH-2) may play a central role in NTG tolerance and cross-tolerance ${ }^{28}$ It remains unknown in the present study whether preventive effects of pioglitazone on NTG-induced impairment of NO bioavailability is due to prevention of oxidative inhibition of ALDH-2. Further studies will be needed to clarify the mechanistic insights into how pioglitazone prevents NTG tolerance and cross-tolerance.

In conclusions, we have shown for the first time that the NTG-induced impairment of NO bioavailability may be improved by the co-treatment with a PPARY agonist, pioglitazone. Furthermore, the catheter-type NO sensor has potential use in the study of the pharmacologic modulation of NO, enabling the measurements of the basal and AChinduced NO production in the aorta of experimental animal models.

\section{References}

1. Schachinger V, Britten MB, Zeiher AM. Prognostic impact of coronary vasodilator dysfunction on adverse long-term outcome of coronary artery disease. Circulation 2000; 101: 1899-1906.

2. Gori T, Mark SS, Kelly S, Parker JD. Evidence supporting abnormalities in nitric oxide synthase function induced by nitroglycerin in humans. J Am Coll Cardiol 2001; 38: 1096-1101.

3. Caramori PR, Adelman AG, Azevedo ER, Newton GE, Parker AB, Parker JD. Therapy with nitroglycerin increases coronary vasoconstriction response to acethylcholine. J Am Coll Cardiol 1998; 32: $1969-1974$.

4. Imanishi T, Kuroi A, Ikejima H, Mochizuki S, Goto M, Akasaka T. Evaluation of pharmacological modulation of nitroglycerin-induced impairment of nitric oxide bioavailability by a catheter-type nitric oxide sensor. Circ J 2007; 71: 1473 - 1479 .

5. Bishop-Bailey D. Peroxisome proliferator-activated receptors in the cardiovascular system. Br J Pharmacol 2000; 129: 823-834.

6. Tao L, Liu HR, Gao E, Teng ZP, Lopez BL, Christopher TA, et al. Antioxidative, antinitrative, and vasculoprotective effects of a peroxisome proliferator-activated receptor-gamma agonist in hypercholesterolemia. Circulation 2003; 108: 2805-2811.

7. Caballero AE, Saouaf R, Lim SC, Hamdy O, Abou-Elenin K, O'Connor $\mathrm{C}$, et al. The effects of troglitazone, an insulin sensitizing agent, on the endothelial function in early and late type 2 diabetes: $\mathrm{A}$ placebo-controlled randomized clinical trial. Metabolism 2003; 52: $173-180$.

8. Mochizuki S, Miyasaka T, Goto M, Ogasawara Y, Yada T, Akiyama $\mathrm{M}$, et al. Measurement of acetylcholine-induced endothelium-derived nitric oxide in aorta using a newly developed catheter-type nitric oxide sensor. Biochem Biophy Res Commun 2003; 306: 505-508.

9. Neishi Y, Mochizuki S, Miyasaka T, Kawamoto T, Kume T, Sukmawan R, et al. Evaluation of bioavailability of nitric oxide in coronary circulation by direct measurement of plasma nitric oxide concentration. PNAS 2005; 102: 11456-11461.

10. Imanishi T, Kobayashi K, Kuroi A, Mochizuki S, Goto M, Yoshida $\mathrm{K}$, et al. Effects of angiotensin II on nitric oxide bioavailability evaluated using a catheter-type nitric oxide sensor. Hypertension 2006; 48: $1058-1065$.

11. Ter Steege JCA, Koster-Kamphuis L, Van Straaten EA, Forget P, Buurman WA. Nitrotyrosine in plasma of celiac disease patients as detected by a new sandwich ELISA. Free Radical Biol \& Med 1998; 25: $953-963$.

12. Fukushima T, Nixon JC. Analysis of reduced forms of biopterin in biological tissues and fluids. Anal Biochem 1980; 102: 176-188.

13. Mochizuki S, Himi N, Miyasaka T, Nakamoto H, Takemoto M, Hirano K, et al. Evaluation of basic performance and applicability of a newly developed in vivo nitric oxide sensor. Physiol Meas 2002; 23: $261-268$.

14. Munzel T, Kurz S, Rajagopalan S, Thoenes M, Berrington WR, Thompson JA, et al. Hydralazine prevents nitroglycerin tolerance by inhibiting activation of a membrane-bound NADH oxidase. J Clin Invest 1996; 98: $1465-1470$.

15. Kurz S, Hink U, Nickenig G, Borthayre AB, Harrison DG, Münzel $\mathrm{T}$, et al. Evidence for a causal role of the renin-angiotensin system in nitrate tolerance. Circulation 1999; 99: 3181-3187.

16. Warnholtz A, Mollnau H, Heitzer T, Kontush A, Möller-Bertram T, Lavall D, et al. Adverse effects of nitroglycerin treatment on endothelial function, vascular nitrotyrosine levels and cGMP-dependent kinase activity in hyperlipidemic rabbits. J Am Coll Cardiol 2002; 40: $1356-1363$.

17. Hink U, Oelze M, Kolb P, Bachschmid M, Zou MH, Daiber A, et al. Role for peroxynitrite in the inhibition of prostacyclin synthase in nitrate tolerance. J Am Coll Cardiol 2003; 42: 1826-1834.

18. Gori T, Mak SS, Kelly S, Parker JD. Evidence supporting abnormalities in nitric oxide synthase function induced by nitroglycerin in humans. J Am Coll Cardiol 2001; 38: 1096-1101.

19. Mochizuki S, Sipkema P, Goto M, Hiramatsu O, Nakamoto H, Toyota E, et al. Exogenous NO suppresses flow-induced endotheliumderived NO production because of depletion of tetrahydrobiopterin. Am J Physiol Heart Circ Physiol 2005; 288: H553-H558.

20. Daiber A, Mulsch A, Hink U, Mollnau H, Warnholtz A, Oelze M, et al. The oxidative stress of nitrate tolerance and the antioxidant properties of hydralazine. Am J Cardiol 2005; 96: 25i-36i.

21. Zierhut $\mathrm{W}$, Ball HA. Prevention of vascular nitroglycerin tolerance by inhibition of protein kinase C. Br J Pharmacol 1996; 119: 3-5.

22. Fleming I, Fisslthaler B, Dimmeler S, Kemp BE, Busse R. Phosphorylation of $\mathrm{Thr}(495)$ regulates $\mathrm{Ca}(2+) /$ calmodulin-dependent endothelial nitric oxide synthase activity. Circ Res 2001; 88: e68-e75.

23. Kähler J, Mendel S, Weckmüller J, Orzechowski HD, Mittmann C, Köster R, et al. Oxidative stress increases synthesis of big endothlein- 1 by activation of the endothelin-1 promotor. $J$ Mol Cell Cardiol 2000; 32: 1429-1437.

24. Kähler J, Ewert A, Weckmüller J, Stobbe S, Mittmann C, Köster R, et al. Oxidative stress increases endothelin-1 synthesis in human coronary artery smooth muscle cells. J Cardiovasc Pharmacol 2001; 38: $49-57$.

25. Munzel T, Giaid A, Kurz S, Stewart DJ, Harrison DG. Evidence for a role of endothelin 1 and protein kinase $\mathrm{C}$ in nitroglycerin tolerance. Proc Natl Acad Sci USA 1995; 92: 5244-5248.

26. Brune B, Schmidt KU, Ullrich V. Activation of soluble guanylate cyclase by carbon monoxide and inhibition by superoxide anion. Eur J Biochem 1990; 192: 683-688.

27. Weber M, Lauer N, Mulsch A, Kojda G. The effect of peroxynitrite on the catalytic activity of soluble guanylyl cyclase. Free Radic Biol Med 2001; 31: 1360-1367.

28. Sydow K, Daiber A, Oelze M, Chen Z, August M, Wendt M, et al. Central role of mitochondrial aldehyde dehydrogenase and reactive oxygen species in nitroglycerin tolerance and cross-tolerance. J Clin Invest 2004; 113: 482-489. 